Revista de Estudios Histórico-Jurídicos

[Sección historia del derecho patrio chileno]

XXXVIII (Valparaíso, Chile, 2016)

[pp. 331 - 355]

\title{
DERECHO Y RELIGIÓN EN LA PRIMERA LEGISLACIÓN CHILENA POSTERIOR A LA LIBERTAD DE CULTOS (1925-1939): DEL ESTADO CONFESIONAL A LA LAICIDAD REALISTA
}

[Law and Religion in the First Chilean Legislation after Freedom of Worship (1925-1939): from a Confessional State to the Realist Laicism]

\author{
Carlos Salinas Araneda* \\ Pontificia Universidad Católica de Valparaíso**
}

\begin{abstract}
RESUMEN
Se estudia la legislación dictada en Chile sobre materia religiosa, desde la entrada en vigencia de la Constitución Política de 1925, en que fue establecida la separación entre el Estado y la Iglesia, hasta el mes de febrero de 1939, en que fallece el papa Pío $\mathrm{XI}$, bajo cuyo pontificado se produjo dicha separación. Se advierte en las autoridades chilenas una actitud de afirmación de la nueva condición de laicidad del Estado, pero sin desconocer la realidad del hecho religioso presente en la sociedad chilena, lo que la lleva a una actitud de reconocimiento y de colaboración que puede calificarse como una laicidad realista.

Palabras clave

Separación Iglesia - Estado - No confesionalidad del Estado - Laicidad del Estado - Laicidad realista.

Abstract

This work studies the legislation enacted in Chile on religious matters, from the entry into force of the Chilean Political Constitution of 1925, wherein the separation between the State and the Church was established, and up to February 1939, when Pius XI, under whose pontificate such separation took place, died. A positive attitude of the Chilean Authorities towards the new secular condition of the State is noticed, but without disregarding the reality of religion present in the Chilean Society, which leads it to an acknowledging and collaboration attitude that may be described as a realist laicism.

\section{KEYWORDS}

Separation of Church - State - NonConfessional State - Laicism of the State - Realist Laicism.
\end{abstract}

ReCIBIDO el 15 de diciembre de 2015 y ACEPTADO el 5 de marzo de 2016

* Catedrático de historia del derecho y derecho canónico en la Pontificia Universidad Católica de Valparaíso. Dirección postal: Facultad de Derecho, Pontificia Universidad Católica de Valparaíso, casilla 4059, Valparaíso, Chile. Dirección electrónica: csalinas@ucv.cl

** Esta investigación ha sido realizada con ocasión del Proyecto Fondecyt 1140891 del que el autor es investigador responsable. 
El 18 de septiembre de 1925 fue promulgada la nueva Constitución Política de la República de Chile, que venía a sustituir a la Constitución que, desde 1833, había regido en el país, una de las Constituciones que más larga duración había tenido en las tres Américas, si bien, con no pocas reformas introducidas a partir de la segunda mitad del siglo XIX. Entre las novedades que traía el nuevo texto constitucional, una no menor fue la separación del Estado y la Iglesia y la consagración de la entonces denominada libertad de cultos ${ }^{1}$. La entrada en vigencia de la nueva Constitución se produjo un mes después, el 18 de octubre de 1925 .

Las relaciones entre el poder espiritual y el poder temporal han existido desde siempre en las sociedades y, por lo mismo, han existido en Chile desde su descubrimiento y conquista. Mientras Chile formó parte de la monarquía hispana, dichas relaciones fueron entre el Estado y la Iglesia católica y que quedaron reguladas institucionalmente bajo la figura del patronato regio ${ }^{2}$. Producida que fue la independencia, las nuevas autoridades chilenas se consideraron herederas del viejo patronato indiano conforme al cual empezaron a actuar desde el primer momento ${ }^{3}$, el que quedó expresamente consignado en diversas disposiciones de la Constitución de $1833^{4}$, la que en su artículo 5, además, había establecido que la religión católica era la religión oficial del Estado ${ }^{5}$. Esta secular relación entre lo temporal y lo espiritual fue sustancialmente modificada por la nueva Constitución de 1925 que encauzó las relaciones entre ambos poderes por la vía de la libertad de cultos, nombre con que se conoció la hoy denominada libertad religiosa.

Un cambio de tal envergadura necesariamente tenía que reflejarse en la legis-

${ }^{1}$ Constitución Política (1925), art. 10: "La Constitución asegura a todos los habitantes de la República: $2^{\circ}$ [inc. $1^{\circ}$ ] La manifestación de todas las creencias, la libertad de conciencia y el ejercicio libre de todos los cultos que no se opongan a la moral, a las buenas costumbres o al orden público, pudiendo, por tanto, las respectivas confesiones religiosas erigir y conservar templos y sus dependencias con las condiciones de seguridad e higiene fijadas por las leyes y ordenanzas. [inc. 20] Las iglesias, las confesiones y las instituciones religiosas de cualquier culto, tendrán los derechos que otorgan y reconocen, con respecto a los bienes, las leyes actualmente en vigor; pero quedarán sometidas, dentro de las garantías de esta Constitución, al derecho común para el ejercicio del dominio de sus bienes futuros. [inc. $3^{\circ}$ ] Los templos y sus dependencias, destinados al servicio de un culto, estarán exentos de contribuciones". Para una bibliografía sobre el tema: SALINAS ARANEDA, Carlos, Lecciones de derecho eclesiástico del Estado de Chile (Valparaíso, Ediciones Universitarias de Valparaíso, 2004), pp. 435-436.

${ }^{2}$ Salinas Araneda, Carlos, Las relaciones Iglesia-Estado en la América indiana: patronato, vicariato, regalismo, en NAVARRO FLORIA, Juan Gregorio (coord.), Estado, derecho y religión en América Latina (Buenos Aires, Marcial Pons, 2009), pp. 17-52; también en NaVARro Floria, Juan G.; Milani, Daniela (a cura di), Le relazioni Chiesa-Stato in America Latina: introduzione storica, en Diritto e religione in America Latina (Bologna, Il Mulino, 2010), pp. 19-67, con bibliografía.

${ }^{3}$ Salinas Araneda, Carlos, Las relaciones Iglesia-Estado en Chile en el siglo XIX, en SÁNCHEZ GaEte, Marcial (dir.), Historia de la Iglesia en Chile, III: Los nuevos caminos: la Iglesia y el Estado (Santiago, Editorial Universitaria, 2011), pp. 231-277.

${ }^{4}$ Constitución Politica (1833), artículos 39 no 3; 82 nos 13, 14; 102; 104 nos 3, 4. Para una visión general SALINAS ARANEDA, Carlos, El factor religioso en las Constituciones de la República de Chile, en MARTín SÁNCHEZ, Isidoro; GonzÁlez SÁNCHEZ, Marcos, 200 años de libertad religiosa en Iberoamérica, número monográfico de Derecho y Religión 7 (Madrid, 2012), pp. 203-230.

${ }^{5}$ Constitución Política (1833), art. 5: "La religión de la República de Chile es la Católica Apostólica Romana; con exclusión del ejercicio público de cualquiera otra". 
lación elaborada por el Estado bajo la inspiración de este nuevo principio. Es lo que pretendo analizar en las páginas que siguen, en el período que va desde el 18 de octubre de 1925, fecha de entrada en vigencia de la nueva Constitución, lo que ocurre bajo el pontificado de Pío XI, y los inicios de 1939, que corresponde al término de su pontificado, ocurrido exactamente el 10 de febrero de ese año.

\section{LAICIDAD REALISTA DEL ESTADO}

De ser un Estado confesional, Chile pasaba a ser un Estado laico, es decir, un Estado sin confesión religiosa. Y ello empezó a advertirse desde el primer momento, pues el Estado empezó a tomar unas iniciativas que obedecían a esta nueva realidad. Con todo, al empezar a tomar decisiones que se avenían con el nuevo estado inaugurado por la nueva Constitución, el gobierno tuvo una posición que podríamos denominar de $\mathrm{l}$ a i c id a d r e a lis t a, pues ellas, aun cuando estuvieron inspiradas en la recién inaugurada laicidad, tuvieron en cuenta la realidad religiosa del país.

\section{Clase de religión}

a) supresión y restablecimiento de la clase de religión

Una de las primeras medidas en este sentido fue la supresión de la clase de religión en las escuelas del Estado. En el mensaje leído por el vicepresidente Carlos Ibáñez del Campo en la apertura de las sesiones ordinarias del Congreso Nacional, el 21 de mayo de $1927^{6}$, daba cuenta de la supresión de las clases de religión "en armonía con los preceptos constitucionales". La decisión, sin embargo, parece que era más por razones económicas que ideológicas, pues un decreto que había sido publicados días antes ${ }^{7}$, que daba cuenta de ese hecho, dejaba constancia que la supresión de las clases de religión había sido "de acuerdo con las disposiciones constitucionales vigentes y con fines de economía". Una decisión tan abrupta en una materia que estaba tan asentada en la sociedad chilena parecía demasiado violenta, razón por la que el mismo presidente de la República, después de haber hecho el anuncio de la supresión de la enseñanza religiosa en los colegios del Estado, agregaba de inmediato en su discurso ante el Congreso, que "como medida de tolerancia, el gobierno ha autorizado el funcionamiento de esa clase dentro de los horarios escolares, sin cargo para el Fisco y con asistencia voluntaria de los alumnos".

En efecto, el 29 de abril inmediatamente anterior, se había promulgado el decreto 1.708 del Ministerio de Educación ${ }^{8}$, según el cual, estimándose que no había razón que impidiese que dichas clases se hicieren para los alumnos cuyos padres lo solicitaren y sin costo para el Fisco, se restablecía "la asignatura de religión, con una hora semanal de clase, en los establecimientos de instrucción secundaria, comercial y normal, dependientes de este ministerio". Dichas clases se harían sin costo para el

\footnotetext{
${ }^{6}$ Diario Oficial (en adelante DO.) 23 mayo 1927.

${ }^{7}$ Decreto 1.708, de instrucción pública, de 1927, en DO. 2 mayo 1927.

${ }^{8}$ Ibíd.
} 
Fisco, se verificarían dentro de horario y la asistencia a las mismas sería obligatoria para los alumnos cuyos padres o apoderados así lo solicitaren por escrito a la dirección del respectivo establecimiento y para aquellos que voluntariamente se matricularen en dicha clase. En el reglamento general de educación primaria dictado a principios del año siguiente ${ }^{9}$, se hacía efectiva esta exención en los siguientes términos: "al efectuarse la matrícula, se dejará constancia por escrito de la exención de la clase de enseñanza religiosa solicitada por el padre o guardador del niño" (art. 7). Todo esto fue recogido en la ley de educación primaria obligatoria de $1930^{10}$.

Hacia fines de $19322^{11}$ se dispuso que " a contar desde el próximo período escolar de 1933, el plan de estudios de educación secundaria" comprendería, junto a las demás asignatura, la de religión, desde el primero al sexto año de humanidades, con tres horas tanto para los liceos de hombres como de niñas.

\section{b) programa de religión}

Supuesto el restablecimiento de la clase de religión, era menester establecer el programa de la materia a enseñar, tarea que asumió el gobierno, tanto para la enseñanza primaria como secundaria ${ }^{12}$. Según dichos programas, en los seis años de enseñanza primaria, los alumnos debían haber adquirido los conocimientos religiosos y morales que se hallan contenidos, como en germen, en la doctrina del Credo, los Mandamientos y demás fórmulas doctrinales y oraciones. Es claro que todo ello conforme a la doctrina de la Iglesia católica. Hacer que los niños comprendiesen estas oraciones y las retuviesen fielmente en la memoria debía ser la labor de los seis años de enseñanza básica. En la enseñanza secundaria había que dar a esos conocimientos un nuevo desarrollo, de acuerdo con el mayor desenvolvimiento de las facultades intelectuales y morales del alumno.

La base y el método en la enseñanza secundaria eran siempre los mismos: el mismo resumen doctrinal de las oraciones, que en la enseñanza secundaria se ampliaba y profundizaba de nuevo, y las narraciones bíblicas con sus auxiliares objetivos, como fundamento concreto e intuitivo de las verdades que se habían de enseñar. Pero con una modificación propia del nuevo grado de enseñanza. En efecto, en la enseñanza primaria, la historia predominaba con la narración ordenada y cronológica de los sucesos, y de estos se derivaban las correspondientes enseñanzas religiosas, sin atender mucho al orden o encadenamiento que estas enseñanzas tuvieran entre sí. En el plan de la enseñanza secundaria debía predominar la enseñanza religiosa con la exposición metódica y ordenada de sus doctrinas y le serviría de auxiliar la historia, suministrando apropiadas narraciones, de cualquiera época que ellas fuesen. En otras palabras la historia serviría al catecismo y no el catecismos a la historia.

La base de las fórmulas doctrinales y oraciones en la enseñanza secundaria serían principalmente cuatro: el Credo, los Mandamientos, las oraciones y los

\footnotetext{
9 Decreto 394, de educación pública, de 1928, en DO. 12 marzo 1928.

${ }^{10}$ Decreto ley 5.291, en DO. 19 mayo 1930, que fija el texto definitivo de la ley de educación primaria obligatoria.

11 Decreto 4.297, de educación pública, de 1932, en DO. 7 noviembre 1932.

12 Decreto 642, de educación pública, de 1929, en DO. 27 mayo 1929.
} 
sacramentos. En torno a ellos debía exponerse todo lo que había que creer, lo que se debía hacer, lo que se debía pedir y lo que se había de recibir. Pero, cuando se presentase la oportunidad, debían recordarse y repasarse las demás fórmulas y oraciones aprendidas anteriormente. Lo propio del sistema gradual y concéntrico era que nada se relegase al olvido, y que en el último año de secundaria los alumnos conservasen frescos los conocimientos adquiridos en todos los años anteriores.

Cada lección constaría de una narración histórica, de las verdades religiosas que de ellas se derivaban y de las aplicaciones morales a la vida de los alumnos. En cada lección, además de la narración histórica, debían citarse otras narraciones que pudiesen también servir de fundamento objetivo a la enseñanza de esa lección, a fin de que el profesor pudiese contarlas y dar más amenidad y variedad a la clase. El orden de la enseñanza en las clases de secundaria sería el mismo de las clases elementales, constando de seis partes: i) el profesor interrogaría a los alumnos acerca de la materia tratada en la clase anterior, a fin de recordar esos conocimientos y poder enlazarlos con los nuevos; ii) enunciaría la nueva materia y narraría la historia que le iba a servir de base concreta y objetiva; iii) haría repetir a los alumnos la historia narrada; iv) la cuarta parte era la principal, y en ella el profesor debía sacar del hecho narrado las enseñanzas dogmáticas y morales que fluían de él, enseñanzas que presentaría en los mismos términos del Catecismo; v) haría repetir estas enseñanzas, varias veces, ya por un alumno, ya por grupos, hasta que todos las grabasen en la memoria; vi) deducirá las enseñanzas morales y las aplicaría a vida actual de los alumnos, moviéndolos eficazmente a ponerlas en práctica.

La materia, para los tres años que comprendían las humanidades, estaba dividida así: primer año, el Credo (26 lecciones); segundo año, los Mandamientos de la Ley de Dios y de la Iglesia (20 lecciones); tercer año, la oración y los sacramentos (29 lecciones). En el segundo año se reducía el número de materias pero se aumentaba el tiempo destinado a tratarlas, a fin de que el profesor pudiera conseguir que los alumnos las aprendiesen bien y pudiesen cimentar sobre bases sólidas sus costumbres morales.

Para los efectos de las calificaciones y exámenes de los alumnos de educación secundaria, las asignaturas se clasificaron en tres grupos: $\mathrm{A}, \mathrm{B}, \mathrm{C}^{13}$. Las del grupo C eran: religión, música y canto, dibujo, caligrafía, trabajos manuales, gimnasia, labores femeninas y economía doméstica.

\section{c) sacerdotes profesores gratuitos de religión}

Si bien el gobierno había dejado sin efecto la supresión de la clase de religión y había restablecido su enseñanza en los establecimientos dependientes del Estado, persistió en su empeño de que dicha enseñanza fuese gratuita, al menos en parte. Consecuente con este interés, en octubre de 1929 dio la posibilidad de que los sacerdotes que lo desearen, se pudieren ofrecer para enseñar gratuitamente religión y moral en las escuelas del Estado, las cuales debían ser efectuadas en

${ }^{13}$ Decreto 2.545, de educación pública, de 1929, en DO. 19 julio 1929. 
conformidad a los programas vigentes y en las horas que fijase el horario escolar para dicha asignatura ${ }^{14}$.

Para ello, los sacerdotes debían presentar una solicitud escrita al Ministerio de Educación, indicando la escuela en que debían hacer sus clases. A dicha solicitud debía acompañarse un certificado de idoneidad otorgado por el ordinario eclesiástico de la diócesis a la que perteneciese el solicitante, exigencia a la que no estaban sometidos los obispos diocesanos, los vicarios apostólicos, los gobernadores eclesiásticos y los canónigos. Todas las solicitudes, sin embargo, debían ir informadas por el director provincial de la jurisdicción escolar correspondiente.

Los sacerdotes que obtenían esta autorización del ministerio, estaban facultados para tomar a su cargo la enseñanza de la asignatura en toda la escuela o en determinados cursos y les correspondía a ellos presentar a los alumnos a las pruebas que fijasen los reglamentos para calificar su aprovechamiento. La autorización se comunicaría para su cumplimiento al solicitante y al director provincial de la respectiva jurisdicción escolar, y mientras estuviesen en el ejercicio de sus funciones, estos sacerdotes tendrían todas las facultades y los deberes que correspondían al personal docente de la escuela. Estos permisos podían suspenderse por un acuerdo del Ministerio de Educación a solicitud de la dirección general de educación primaria, acompañando los antecedentes que justificarían tal medida.

La respuestas de los sacerdotes fue generosa, pues en los meses sucesivos fueron publicándose en el Diario Oficial, individualmente o en listas más o menos extensas, los nombres de numerosos sacerdotes que respondieron a esta nueva dimensión apostólica que les ofrecía el Estado de Chile que estrenaba su laicidad. No sólo sacerdotes de Santiago ${ }^{15}$ y otros lugares del país ${ }^{16}$, sino también sacerdotes constituidos en dignidad ${ }^{17}$; no sólo presbíteros seculares sino también regulares. Desde esta perspectiva, en consecuencia, la generosidad de los sacerdotes que se ofrecieron como profesores gratuitos de religión en colegios del Estado es digna de alabar y de agradecer. El Estado, sin embargo, se reservaba el derecho de no otorgar dicha autorización, y hay constancia de que ello ocurrió en alguna ocasión ${ }^{18}$.

Cuando en 1930 se dictó la ley de educación primaria obligatoria ${ }^{19}$, se reiteró la posibilidad de que los sacerdotes que lo quisieren pudieren gratuitamente dar

14 Decreto 1.069, de educación pública, de 1929, minuta, en DO. 16 octubre 1929.

15 P. ej. por decreto 5.999, de educación pública, de 1930, se autorizó al presbítero don Ramón Munita Eyzaguirre para que, en conformidad a lo dispuesto en el decreto 1.069, de abril de 1929, impartiera enseñanza religiosa en las escuelas números 42 y 149 del departamento de Santiago, DO. 8 noviembre 1930.

${ }^{16}$ Arauco, Caupolicán, Chillán, Concepción, Copiapó, Coronel, Curicó, Imperial, Itata, La Laja, La Serena, La Unión, Lautaro, Linares, Los Andes, Maipo, Melipilla, Mulchén, Osorno, Ovalle, Petorca, Pisagua, Quillota, Quintero, Rancagua, San Felipe, Santa Cruz, Temuco, Tomé, Valdivia, Valparaíso, Villarrica, Yumbel, Yungay, etc.

${ }_{17}$ Miguel Alvear, vicario general del obispado de Temuco, en la escuela no 1 de esa ciudad. Decreto s/n, de educación pública, minuta, en DO. 23 noviembre 1929.

${ }_{18}$ No se dio lugar a la solicitud del presbítero Rafael Azócar para impartir enseñanza religiosa en las escuelas del departamento de La Unión, pero no se indica la razón. Decreto 4.008, de educación pública, de 1930, minuta, en DO. 12 julio 1930.

19 Véase antes nota 10. 
clases de religión en estos establecimientos (art. 25).En 1934, sin embargo, se establecieron algunas exigencias para que las personas que se habían ofrecido para impartir gratuitamente clases de religión, pudieran hacerlo, en atención a que la ley de educación primaria obligatoria disponía que todo postulante, para poder ingresar al servicio, además de ser chileno, debía estar en posesión de un título expedido o reconocido por el Estado, que habilitase para la enseñanza de la rama o asignatura de que se tratase (art. 70), exigencia que reiteraba el reglamento de escalafón (art. 7). Por otra parte, el reglamento general de educación primaria ${ }^{20}$ disponía que la enseñanza debía ser más formativa que informativa, de manera que presentase organizada las materias en forma coherente y que existiese entre todos los conocimientos y actividades de las diferentes asignaturas, la natural unidad y correlación, todo lo cual era imposible conseguir por el profesor si no tenía el dominio de las ciencias y técnicas de la educación (art. 140). A la luz de lo anterior, se dispuso ${ }^{21}$ que, además del certificado de idoneidad que debía adjuntarse a la solicitud, los postulantes debían estar en posesión de un título expedido o reconocido por el Estado, que habilitase para la enseñanza de la religión y moral. En su defecto, debían rendir un examen sobre teoría y práctica pedagógica para la enseñanza de la religión, de acuerdo con los programas aprobados por decreto supremo, ante una comisión designada por la dirección general de educación primaria y compuesta por un profesor de metodología y pedagogía de escuela normal, que la presidiría, de un profesor de religión de escuela normal y de un profesor de religión de liceo. Algunos meses después"2, se aprobó el "reglamento para el examen de pedagogía y metodología de la enseñanza de la religión”, examen que constaría de una prueba escrita y de una clase de práctica (art. 4), y se aprobó también el "programa de pedagogía y metodología de la enseñanza de la religión".

\section{Matrimonio civil}

En 1884 se dictó en Chile la primera ley de matrimonio civil que vino a establecer el matrimonio civil como el único matrimonio válido ante el Estado ${ }^{23}$. Dicha ley vino a poner fin al reconocimiento que, hasta su entrada en vigencia, había tenido el matrimonio canónico, cuya validez había sido expresamente establecida por el Código Civil en 1855 (art. 103, 117). A partir de 1884, "el matrimonio que no se celebre con arreglo a las disposiciones de esta ley [de matrimonio civil], no produce efectos civiles (art. 1 inc. $1^{\circ}$ ). No se prohibía, empero la realización de matrimonios religiosos, pues la misma ley disponía que "es libre para los contrayentes sujetarse o no a los requisitos y formalidades que prescribe la religión a que pertenecieren" (art. 1 inc. $2^{\circ}$ ). Pero inmediatamente agregaba que "no se tomará en cuenta esos requisitos y formalidades para decidir sobre la validez del matrimonio ni para reglar sus efectos civiles" (art. 1 inc. $3^{\circ}$ ).

La ley de matrimonio civil, sin embargo, no estableció la precedencia obliga-

\footnotetext{
20 Decreto 394, de educación pública, de 1928, en DO. 12 marzo 1928.

21 Decreto 5.523, de educación pública, de 1933, en DO. 16 enero 1934.

22 Decreto 6.477, de educación pública, de 1934, en DO. 29 noviembre 1934.

${ }^{23}$ Ley de 10 de enero de 1884, en Boletín de Leyes (1884), pp. 148-160.
} 
toria del matrimonio civil respecto del matrimonio religioso, lo que era lógico, porque la ley no otorgaba a éste ninguna relevancia legal. Pero se suscitó un problema de hecho que vino a poner sobre el tapete la posibilidad de esa precedencia; la existencia paralela de ambos matrimonio, el civil y el canónico, dio origen a un abuso: la celebración del matrimonio civil con una pareja y del matrimonio canónico con otra. En el mensaje leído por el presidente Juan Luis Sanfuentes (1915-1920) en la apertura de las sesiones ordinarias del Congreso Nacional del año $1916^{24}$, reconocía que "las disposiciones vigentes sobre matrimonio" continuaban dando origen a abusos que era indispensable conjurar, para lo cual "el gobierno penetrado de la necesidad de asegurar la correcta constitución de la familia, y dentro de la armonía que anhela mantener en sus relaciones con la Iglesia, procura con especial interés dar a este asunto una solución patriótica, tranquila y que pueda ser de general aceptación”. La solución al problema vino de los propios obispos quienes, previa autorización de la Santa Sede, impusieron a los fieles que se casaban canónicamente la obligación de hacerlo también civilmente, con lo cual se vio superado el problema y, si bien el matrimonio canónico no fue reconocido por la ley civil ${ }^{25}$, tampoco se estableció la precedencia del matrimonio civil respecto del canónico. No hay que olvidar, sin embargo, que por esos años todavía estaba vigente la Constitución de 1833 que establecía la confesionalidad del Estado, lo que limitaba, de alguna manera, el actuar del Estado.

Con la nueva Constitución las condiciones que hacían aconsejable no imponer la precedencia del matrimonio civil respecto del canónico ya no existían, pues el nuevo régimen de libertad de cultos separaba claramente lo temporal de lo religioso. De hecho, el primer gobierno de Carlos Ibáñez del Campo tuvo redactado un decreto con fuerza de ley en tal sentido, que el presidente finalmente no firmó ${ }^{26}$. Pero el tema del matrimonio civil y sus relaciones con el canónico estaba presente cuando, en 1930, se promulgó la ley de registro civil la que, si bien no llegó a fijar dicha precedencia, estableció un plazo perentorio para celebrar el matrimonio civil si a éste le había precedido el matrimonio religioso, estableciendo penas de multa y hasta de cárcel a quienes no lo hicieran.

${ }^{24} 1^{\circ}$ de junio de 1916. Mensaje leido por S. E. el Presidente de la República en la apertura de las sesiones ordinarias del Congreso Nacional (Santiago, Imprenta Nacional, 1916), pp. 8-9.

25 "El Santo Padre se ha dignado manifestarnos, por medio de la nunciatura apostólica, que 'ha visto con satisfacción la iniciativa del episcopado chileno', y se ha servido 'aprobar el juicio de los obispos, ora en lo que se refiere a la grave obligación de conciencia, por la cual, en las actuales circunstancias, por el propio bien como por el de la prole, ex praesumptione communis periculi, están obligados los fieles chilenos a hacer inscribir los propios matrimonios en el registro civil; ora en lo que concierne a la necesidad de que las autoridades eclesiásticas locales procedan a hacer una declaración pública sobre la misma obligación". Circular colectiva del episcopado chileno, de 26 de diciembre de 1919, en Boletín Eclesiástico del Arzobispado de Santiago 21 (1919-1929), pp. 448-453.

${ }^{26}$ Somarriva Undurraga, Manuel, Evolución del Código Civil Chileno (Santiago, Editorial Nascimento, 1955), pp. 52-55. 


\section{Algunas limitaciones a la religión}

En 1929 se dictó una nueva ley electoral ${ }^{27}$, en la cual se negaba la inscripción, aunque cumplieran los requisitos generales, a "los eclesiásticos regulares" (art. 24 $\left.n^{\circ} 5\right)$. Se trataba de una prohibición que venía de antes, pues la ley electoral de 1890 contemplaba la misma limitación (art. 26 no 9) y había dado origen a algún pronunciamiento judicial con ocasión de una petición de dos religiosos profesores del Curso de Leyes de los Sagrados Corazones de Valparaíso, en el que se razonaba que la intención o espíritu de la ley era privar de sufragio a todos los religiosos por carecer de la libertad necesaria, pues, por el voto de obediencia se obligaban no sólo a hacer lo que el superior les ordenaba y no hacer lo que el superior les prohibía, sino a no hacer nada, por poco considerable que fuere, sin permiso del superior $^{28}$. Una limitación similar dispuso la ley sobre elecciones y organización municipales ${ }^{29}$ la que, al regular el registro de quienes podían intervenir en las elecciones de regidores municipales, dispuso que no podrían inscribirse, aun cuando cumplieren los requisitos definidos por la misma ley, "los eclesiásticos regulares" (art. $20 \mathrm{n}^{\circ}$ 2).

La ley de adopción ${ }^{30}$ estableció una nueva limitación, pues disponía que no podrían adoptar "los eclesiásticos seculares y los religiosos de uno y otro sexo" (art. 3).

\section{RECONOCIMIENTO DEL HECHO RELIGIOSO}

COMO FACTOR SOCIAL

La laicidad del Estado inaugurada por la Constitución de 1925 llevó a los gobernantes, como hemos visto, a empezar a tomar decisiones directamente inspiradas en ella, pero con una mirada realista de lo que por entonces ocurría en Chile en materia religiosa, lo que los llevó a reconocer el hecho religioso como un factor social presente en la sociedad, que no podía desconocerse sin más. En otras palabras, el Estado se hace eco de lo religioso en sus leyes y en su actuar, no en cuanto es religioso, sino en cuanto es una dimensión social presente en la sociedad, como lo puede ser el deporte o la cultura, que también merecen el reconocimiento del Estado, pero no porque el Estado sea deportista o culto -el Estado en cuanto Estado es incapaz de ello-, sino en cuanto ambos son factores sociales que ameritan el reconocimiento del Estado y, como veremos, la consecuente colaboración.

27 Ley 4.554, de 9 de febrero de 1929, en DO. 12 febrero 1929.

${ }^{28}$ Salinas Araneda, Carlos, 120 años enseñando el derecho. Noticias biográficas de los profesores fallecidos del Curso de Leyes de los Sagrados Corazones de Valparaíso y de la Escuela de Derecho de la Pontificia Universidad Católica de Valparaíso (Valparaíso, Ediciones Universitarias de Valparaíso, 2014), pp. 213-216, 312-313.

${ }^{29}$ Ley 5.357, en DO. 18 enero 1934. Decreto 1.622, de interior, de 1934, que fija el texto definitivo de la ley de organización y atribuciones de las municipalidades, en DO. 5 mayo 1934, art. 20 no 2.

${ }^{30}$ Ley 5.343 , en DO. 6 enero 1934. 
Este reconocimiento de lo religioso como factor social se advierte de diversas maneras.

1. Trato especial a la Iglesia católica inmediatamente después de la separación Estado-Iglesia

Esto se tradujo en variadas decisiones como la indemnización a la Iglesia católica establecida en la primera de las disposiciones transitorias de la nueva Constitución, en la renta vitalicia para el arzobispo de Santiago $^{31}$, o en la jubilación facilitada a los funcionarios eclesiásticos. En efecto, la Constitución debía entrar en vigencia el 18 de octubre de 1925, lo que significaba que los funcionarios eclesiásticos, como consecuencia de la separación Estado-Iglesia, dejaban de serlos, con la consecuente cesación del pago de sus remuneraciones las que, sin embargo, serían pagadas hasta el 31 de diciembre de ese año, fecha hasta la que regía la ley de presupuesto correspondiente a ese año, en la que dichas remuneraciones estaban contempladas, pues desde 1926 dejaba de existir el presupuesto del culto. Esto motivó otra decisión del Estado en beneficio de la Iglesia católica, pues, mediante un nuevo decreto $l e y^{32}$, se concedió el beneficio de la jubilación a los funcionarios eclesiásticos.

La razón que proporcionaba el decreto ley es digna de recordar: "es de toda justicia procurar los beneficios de la jubilación [...] a dichos funcionarios eclesiásticos que han sido ejecutores de la benéfica obra moralizadora y cultural realizada por la Iglesia en el pais". Pero había también una razón práctica no menor: "que la exigüidad de las rentas de que gozan los aludidos funcionarios, hará que no sea muy gravosa la carga pecuniaria que representarán las jubilaciones de que se trata". Conforme a ello, el decreto ley dispuso que "los funcionarios eclesiásticos que actualmente perciben rentas del Estado con cargo al presupuesto del culto, podrán acogerse, desde esta fecha y hasta el 31 de diciembre del año en curso, a los beneficios de la jubilación, la que será concedida de conformidad a las disposiciones generales vigentes sobre la materia".

Aparte de los ejemplos anteriores, hay que mencionar el reconocimiento de la dimensión internacional de lo religioso, pues Chile siguió manteniendo relaciones diplomáticas con la Santa Sede.

\section{Educación}

El munus docendi de la Iglesia católica es una dimensión esencial de su actuar, materializada en múltiples iniciativas que el Estado no pudo desconocer, reconocimiento que se manifestó de diversas maneras, entre las que destacan:

a) declaración de cooperadores de la función educacional del Estado y autorización para instalar nuevos centros educativos

Fue otra manera de reconocer lo religioso; por decreto se declaraba a esta-

31 Decreto ley 537, de 21 de septiembre de 1925, publicado en DO. 22 septiembre 1925.

32 Decreto ley 586, de 29 de septiembre de 1925, publicado en DO. 6 octubre 1925. 
blecimientos de educación pertenecientes a instituciones religiosas la calidad de cooperadores de la función educacional del Estado, lo que se hizo tanto con universidades, como la Universidad Católica de Valparaíso ${ }^{33}$; cursos universitarios, como el Curso Universitario de los Sagrados Corazones de Valparaíso ${ }^{34}$; establecimientos de educación primaria sostenidas por obispados ${ }^{35}$, parroquias $^{36}$, congregaciones $^{37}$ o misiones ${ }^{38}$; y también escuelas sostenidas por otras confesiones religiosas, como las escuelas metodistas ubicadas en Peleco y Mañío, en el departamento de Imperial ${ }^{39}$; la escuela evangélica alemana, en Chamiza, departamento de Llanquihue $^{40}$; o la escuela sostenida por la Institución Sweet bajo la dependencia de la Iglesia metodista episcopal ${ }^{41}$.

Pero no sólo declarar cooperadores del Estado a colegios que funcionaban a cargo de personas o instituciones religiosas, sino también autorizar la apertura de nuevos colegios, como el decreto ${ }^{42}$ que autorizó la apertura de un colegio particular de enseñanza que funcionaría en la ciudad de San Fernando, dirigido por la Congregación de los Hermanos Maristas; o de un colegio particular de segunda enseñanza en Santiago, que se denominaría Colegio Santa Filomena, bajo la dirección de la Congregación de las Hijas de San José Protectoras de la Infancia $^{43}$. Además, a comienzos de $1933^{44}$, se autorizó a las Hijas de María Auxiliadora para establecer en Santiago una escuela normal, la que debía ceñirse a los reglamentos, programas y planes de estudio de las escuelas normales del Estado, y cuyo alumnado sería formado exclusivamente por novicias religiosas de dicha congregación. La referida escuela normal estaría destinada solamente a la preparación de profesores para las escuelas particulares que sostenía esa congregación, y el título que otorgaría a las alumnas que completasen el curso oficial de estudios y rindiesen, ante comisiones designadas por el Estado, las pruebas anuales y finales correspondientes, sería el de profesora primaria particular.

33 Decreto 5.014, de educación pública, de 1929, minuta, en DO. 30 julio 1929.

${ }^{34}$ Decreto 3.975, de educación pública, de 1929, minuta, en DO. 27 mayo 1929.

35 P. ej. la escuela Justo Donoso, sostenida por el obispado de La Serena, o la escuela Carlos Walker, sostenida por el obispado de Rancagua. Decreto 3.160, de educación pública, de 1929, minuta, en DO. 4 julio 1929.

${ }^{36}$ P. ej. la escuela parroquial Santa Cruz de Triana, sostenida por la parroquia del mismo lugar, en el departamento de Rancagua; la escuela El Perpetuo Socorro, sostenida por la parroquia de Chimbarongo. Decreto 3.160, educación pública, de 1929, minuta, en DO. 4 julio 1929.

37 P. ej. la escuela Providencia, en La Serena, sostenida por la Congregación de la Providencia; la escuela Sargento Aldea, en Chimbarongo, sostenida por la Congregación Mercedaria. Decreto 3.160, de educación pública, de 1929, minuta, en DO. 4 julio 1929.

${ }^{38}$ P. ej. el internado de hombres y el liceo de niñas de la Misión Araucana ubicadas en Cholchol, o la escuela rural de la Misión Araucana ubicada en Botrohue, decreto 5.811, de educación pública, de 1929, en DO. 19 agosto 1929.

39 Decreto 688, de educación pública, de 1938, minuta, en DO. 3 mayo 1938.

40 Ibíd.

${ }^{41}$ Decreto 2.333, de educación pública, de 1939, minuta, en DO. 26 mayo 1939.

${ }^{42}$ Decreto 157, de educación pública, de 1931, minuta, en DO. 18 abril 1931.

${ }^{43}$ Decreto 1.791, de educación pública, de 1931, minuta, en DO. 25 junio 1931.

${ }^{44}$ Decreto 3.229, de educación pública, de 1933, en DO. 11 enero 1933. 


\section{b) autorización a religiosas para ejercer el magisterio}

Para ejercer el magisterio en las escuelas primarias era preciso cumplir las exigencias establecidas en el reglamento general de las escuelas primarias, aprobado por decreto 3.060, de 6 de agosto de 1929, requisitos del que, sin embargo, fueron eximidas las religiosas de la Congregación Hermanas de la Santa Cruz, las que fueron autorizadas para ejercer el magisterio en los establecimientos sostenidos por dicha Congregación, dedicados a la educación de los niños indígenas del país. El decreto $^{45}$ que les otorgaba el beneficio, que contaba con la aprobación del rector de la Universidad de Chile, incluía el nombre de 83 religiosas que quedaban eximidas del cumplimiento de la obligación contenida en el artículo 118 del reglamento. El mismo decreto incluía el nombre de otras 58 religiosas que quedaban exceptuadas de lo dispuesto en el artículo 113 de aquel decreto para que pudieran "hacer clases de idioma nacional, geografía, historia patria y educación cívica". La misma autorización para ejercer el magisterio, como profesoras primarias, en los establecimientos sostenidos por sus respectivas congregaciones se otorgó a 17 religiosas de la Congregación del Sagrado Corazón de Jesús, ocho religiosas de la Congregación Carmelitas de la Caridad, y 13 religiosas de la Congregación del Patronato de San Antonio ${ }^{46}$.

c) validez de exámenes de los alumnos de los seminarios conciliares

La ley de 9 de enero de $1879^{47}$, sobre instrucción secundaria y superior, había dispuesto en su artículo 41 inciso $6^{\circ}$, que eran válidos para obtener grados en la Facultad de Filosofía y Humanidades y en la de Teología, los exámenes rendidos ante sus propios profesores por los alumnos de determinados seminarios. Dicha ley, empero, fue derogada por el decreto 5.146, de 14 de noviembre de $1929^{48}$, dictado en uso de las facultades extraordinarias de que gozaba el gobierno, pero dicha disposición no había sido reproducida en las leyes o decretos con fuerza de ley dictados con posterioridad sobre la materia. Como el gobierno considerase conveniente que dicha disposición se conservase, haciendo uso de las facultades que le confería la ley $4.659^{49}$, dispuso que serían válidos para las promociones dentro del primer y segundo ciclos de la enseñanza media y para los efectos de la licencia secundaria, los exámenes rendidos ante sus propios profesores los alumnos de los seminarios conciliares de La Serena, Santiago, Concepción y Ancud, y de los colegios seminarios de Valparaíso y Talca ${ }^{50}$.

En el mismo decreto se autorizaba a dichos establecimientos y demás colegios

45 Decreto 4.892, de educación pública, de 1930, en DO. 25 septiembre 1930.

46 Decreto 1.432, de educación pública, de 1931, minuta, en DO. 22 junio 1931. Otro tanto se hace en el decreto 1.461 , de educación pública, del mismo año, minuta, en $D O .23$ junio 1931.

${ }^{47}$ DO. 13 enero 1879.

48 Véase antes nota 30.

49 Autorizó al presidente de la República para dar término a la reorganización administrativa y técnica de los servicios educacionales, en DO. 24 septiembre 1929.

50 Decreto 5.232, de educación pública, de 1929, publicado en DO. 29 noviembre 1929. Fue reiterado por decreto 5.369 (5.232), de educación pública, de 1930, publicado en DO. 8 octubre 1930 . 
destinados a preparar jóvenes para la carrera eclesiástica, que pudieren reemplazar la lengua latina por uno de los idiomas consultados en el plan de estudios de la educación secundaria, y consultarse en el plan diferenciado del segundo ciclo, asignaturas especiales o intensificaciones de ramos comunes que se relacionasen con dicha carrera. No fueron los únicos, porque en 1933 se autorizó al obispo de Iquique, Carlos Labbé, para fundar en dicha ciudad un colegio de segunda enseñanza, con el nombre de Seminario Diocesano ${ }^{51}$.

\section{Hospitales}

La presencia religiosa fue igualmente respetada y regulada en los hospitales, en los que no sólo se reconocía la presencia de capellanes y religiosas, sino que sus labores quedaban expresamente reguladas por la norma estatal. Ejemplo de ello es el reglamento del hospital San Esteban de Cañete ${ }^{52}$, en cuyo artículo $3^{\circ}$ se afirmaba que el hospital, bajo la dirección de un director y sub-director, sería servido, entre otros, por religiosas y un capellán (art. 3); a falta de aquellas, sus obligaciones serían desempeñadas por el personal laico que se nombrare en su reemplazo (art. 4).

En lo referido a las religiosas, disponía el reglamento que la superiora de las religiosas estaría encargada de la economía interior del establecimiento y de la inspección de los artículos de consumo, rechazando los que no se encontraren en buenas condiciones y vigilando que las atenciones higiénicas, médicas y dietéticas fuesen cumplidas pronta y eficazmente; en general, ejercería la supervigilancia del personal auxiliar y subalterno, dando cuenta a la dirección de las faltas que notare (art. 38). Tenía a su cargo, además, los vasos sagrados, paramentos sacerdotales y demás objetos destinados al culto divino, así como las ropas, útiles, medicinas, instrumentos de cirugía y demás enseres del establecimiento, debidamente inventariados (art. 39).Las religiosas atenderían los departamentos que la superiora les señalare, cuidando que los enfermos y empleados subalternos cumplieran con sus obligaciones; y que la dieta, medicamentos y demás prescripciones se efectuaren de acuerdo con las indicaciones médicas (art. 40). Entre las religiosas habría una que tendría a su cargo la llave de la puerta del establecimiento, pudiendo disponer de una empleada para el servicio de ella (art. 41); cuando, fuera de la hora de visita del médico, ocurriere un caso grave y urgente debía ponerlo inmediatamente en su conocimiento, para que éste lo resolviera (art. 42). En la visita del médico, éste debía ser acompañado por la monja y practicante de la sala (art. 20).

En cuanto al capellán ${ }^{53}$, era nombrado directamente por la Junta de Beneficencia, con la obligación de suministrar a los enfermos que voluntariamente lo

51 Decreto 1.190, de educación pública, de 1933, DO. 4 agosto 1933.

${ }^{52}$ Decreto 48, de higiene, asistencia, previsión social y trabajo, de 1926, en DO. 19 febrero 1926.

53 Por razones de espacio he debido dejar de lado el tema de los capellanes castrenses, respecto de los cuales hay numerosas normas dictadas en estos años, tanto para los capellanes del ejército y la armada, como para los capellanes de carabineros, institución creada por estos años por el presidente Carlos Ibáñez del Campo. Sobre el vicariato castrense de Chile puede verse GonZÁLEZ 
solicitaren, los servicios religiosos (art. 43). Lo correspondía, además, celebrar Misa en el establecimiento los días y horas que le señalare la dirección, de acuerdo con la superiora (art. 44), con la cual debía también acordar el servicio religioso de la comunidad (art. 45).

Hubo otros hospitales en los que expresamente se consideraba la presencia de hermanas de la caridad, como el hospital san Vicente de Paul de Santiago, en el que se contemplaban 32 hermanas, dos capellanes y un sacristán ${ }^{54}$.

\section{Cementerios}

Para cuando entró en vigencia la nueva Constitución, el problema de los cementerios que había suscitado apasionadas controversias en el siglo anterior estaba superado ${ }^{55}$ y no sólo era pacífica la existencia de los cementerios municipales, sino que en las normas a ellos referidas, mientras se hacía referencia a que estaban destinados a la sepultación "de cadáveres de toda persona, cualquiera que hubiere sido su religión y nacionalidad”, se especificaba que partes del mismo estaban destinadas "a sepulturas de familias y corporaciones ya sean civiles o religiosas" hubo, incluso, que contemplaban sepultura "para las corporaciones, sean civiles 0 religiosas que tengan o no personalidad juridica" 57 .

Las referencias a las congregaciones religiosas fue permanente en estos reglamentos, en los que, a veces, se las diferenciaba de las instituciones de derecho público. Así, en un reglamento ${ }^{58}$, se especificaba que las sepulturas de primera categoría la constituirían las bóvedas y mausoleos, los que se destinaban a los particulares, a las familias, "a las sociedades con personería jurídica, a las congregaciones religiosas y a las instituciones de derecho público".

Hay algún reglamento, como el del cementerio de Nueva Imperial ${ }^{59}$, que expresamente permite, si lo desean los deudos, colocar en las sepulturas "epitafios de carácter religioso".

5. Concesiones a ministros de culto y religiosos

El reconocimiento de lo religioso como factor social presente en la sociedad

Errázuriz, Juan Ignacio, El vicariato castrense de Chile (Santiago, Ediciones Universidad de los Andes, 1996); MatTe Varas, Joaquín, Historia del obispado castrense de Chile (Santiago, 2010).

${ }^{54}$ Decreto 1.240, de 1930, minuta, en DO. 14 abril 1930.

${ }^{55}$ LEÓn LeÓn, Marco Antonio, Sepultura sagrada tumba profana. Los espacios de la muerte en Santiago de Chile, 1888-1932 (Santiago, Dirección de Bibliotecas, Archivos y Museos, Lom Ediciones, 1997).

${ }^{56}$ Reglamento del cementerio de Quilpué, en decreto 268, de higiene, asistencia, previsión social y trabajo, de 1926, en DO. 27 mayo 1926.

${ }^{57}$ Reglamento del cementerio general de Puerto Montt, decreto 2.275, de bienestar social, de 1929, en DO. 13 diciembre 1929.

58 Reglamento del cementerio de Ancud, en decreto 2.187, de bienestar social, de 1928, en DO. 5 diciembre 1928.

59 Reglamento del cementerio de Nueva Imperial, decreto 417, de bienestar social, de 1929, en DO. 10 agosto 1929. 
llevó a las autoridades del Estado a hacer algunas concesiones a quienes formaban parte de entidades religiosas, respetuosa del estado de vida que habían asumido, como la exención del servicio militar ${ }^{60}$ o la exención de obtener la cédula de identidad $^{61}$; pero ocasiones hubo que dichas concesiones beneficiaban al propio Estado, como la autorización a los párrocos para requerir inscripciones de nacimiento en el registro civil. El reglamento orgánico del registro civil ${ }^{62}$ disponía en su artículo 122 que el requerimiento escrito para practicar una inscripción de nacimiento debía llevar, entre otros, una certificación del nacimiento otorgada por el médico o partera que lo hubiere presenciado. La falta de este certificado podía suplirse por la certificación hecha por individuos especialmente autorizados para ello por el conservador del registro civil, para lo cual cada oficial civil debía llevar un registro especial con las firmas e impresiones digitales de las personas que hubieren recibido la autorización antedicha. En cumplimiento de esta norma reglamentaria, una orden de servicio ${ }^{63}$ dispuso que quedaban autorizados los oficiales del registro civil para inscribir en el registro especial referido por el artículo 122 del reglamento, la firma e impresión digital de los párrocos con jurisdicción sobre todo o parte del territorio de la circunscripción.

\section{Honores}

El reconocimiento de lo religioso como factor presente en la sociedad llevó a las autoridades a conceder diversos honores a personas vinculadas a lo religioso, honores que asumieron modalidades diversas, como la concesión de condecora-

${ }^{60}$ Las normas que por estos años se dictan para regular el servicio militar (decreto con fuerza de ley 31, de 12 de marzo de 1931, en DO. 17 marzo 1931) dispusieron expresamente la exención de las obligaciones militares de "los ministros de cualquier culto, los que hubieren recibido órdenes y los religiosos profesos" ( $a r t .50 \mathrm{n}^{\circ} \mathrm{6}$ ). La norma claramente beneficiaba a personas pertenecientes a la Iglesia católica y era respetuosa con el derecho de la Iglesia que en el Código de Derecho Canónico (1917) disponía que "todos los clérigos están exentos del servicio militar" (canon 121). Pero como el Estado de Chile había dejado de ser confesional, la exención había que extenderla a todos los ministros de culto. Dichas calidades había que comprobarlas con "un certificado de un obispo o de la autoridad religiosa correspondiente". El beneficio se extendía a los estudiantes eclesiásticos, pero no para quedar exentos del servicio militar, sino sólo para obtener la postergación del mismo, sin perjuicio de quedar exentos del mismo, si les correspondía.

${ }^{61}$ La ley 4.237, de 30 de diciembre de 1927, dispuso que estaban obligados a obtener su libreta de identidad personal, todas las personas residentes en el territorio de la República, tanto nacionales como extranjeros, que hubiesen cumplido 21 años, libreta que debía renovarse cada cinco años. Había, sin embargo, algunas personas exceptuadas, entre las que se contaban "los religiosos enclaustrados" (art. 5 inc. $2^{\circ}$ ).

${ }^{62}$ Decreto con fuerza de ley 2.128, de 10 de agosto de 1930, en DO. 28 agosto 1930.

${ }^{63}$ DO. 28 octubre 1930. 
ciones $^{64}$, cartas de nacionalización ${ }^{65}$, honras especiales en funerales ${ }^{66}$ o la erección de monumentos ${ }^{67}$.

\section{La bandera de Chile en la basílica de San Francisco, en Mendoza}

En el convento de la Orden de San Francisco, en Mendoza, existe una imagen de la Virgen del Carmen, bajo cuyos auspicios José de San Martín puso al ejército de los Andes y a la cual entregó el bastón de mando que dicha imagen aún conservaba en 1928. Tanto los gobiernos de Argentina como del Perú habían autorizado, por decreto, el uso de los respectivos pabellones nacionales dentro de la iglesia de dicho convento que había sido declarado monumento nacional por el gobierno argentino, indicado como un homenaje a ese recuerdo histórico. La embajada de Chile en Buenos Aires transmitió al gobierno de Chile una petición del superior de la comunidad de franciscanos para que el gobierno de Chile autorizase, también por decreto, el uso de la bandera de Chile, a fin de colocarla junto con las de Argentina y de Perú, como testimonio perenne de glorias comunes. El gobierno de Chile acogió favorablemente la petición y, mediante decreto ${ }^{68}$, facultó a la basílica de San Francisco, en Mendoza, para que usase oficialmente la bandera de Chile, en el santuario de la Virgen del Carmen de Cuyo.

Posteriormente, se disponía que se pagara la suma de $\$ 4.000$, valor de una placa de bronce que contenía el decreto que, en 1928, autorizaba el uso del pabellón chileno en el santuario de la Virgen del Carmen de Cuyo, en la provincia de Mendoza ${ }^{69}$.

${ }^{64}$ P. ej. por decreto 391, de relaciones exteriores, de 1926, minuta, en $D O .3$ agosto 1926 , se concedió la condecoración "al mérito" a la hermana Agustina, del hospital San Juan de Dios, de Valparaíso; por decreto 1.121, de relaciones exteriores y comercio, de 1930, minuta, en DO. 4 agosto 1930, se le otorgó al sacerdote francés Emilio Velasco, en el grado de comendador.

${ }^{65}$ Como la que se concedió a Guido Beck de Ramberga, ofm. cap., en 1930, quien, en 1928, había sido nombrado obispo titular de Mastaura por Pío XI y vario apostólico de Araucanía. Decreto 4.252, de interior, de 1930, minuta, en DO. 18 julio 1930.

${ }^{66}$ Cuando falleció el arzobispo de Santiago, Crescente Errázuriz Valdivieso, se decretaron honores especiales en sus funerales, teniendo presente "los eminentes servicios prestados a la República”. Decreto 605 bis, de relaciones exteriores y comercio, de 1931, en DO. 24 junio 1931.

${ }^{67} \mathrm{Al}$ mismo arzobispo se le concedió otro honor cuando se acordó la erección de un monumento para honrar su memoria, costeado por suscripción popular, el que debía colocarse en la plazoleta situada entre las calles Merced y Mac-Iver, plazoleta que llevaría su nombre (ley 5.144, en DO. 21 marzo 1933). Poco después, se autorizaba a la comisión central pro monumento al arzobispo, para llevar a efecto una colecta pública, en todo el territorio nacional, a fin de reunir fondos destinados a la erección del mismo (decreto 1.867, de interior, de 1933, en DO. 17 mayo 1933). Posteriormente, mediante una nueva ley (ley 5.190, en DO. 11 julio 1933),se autorizó al presidente de la República para fijar la ubicación que estimare más conveniente para este monumento. En uso de esta autorización, dispuso que quedara erigido en la plazuela de la Merced (decreto 4075, de interior, de 1933, en DO. 20 octubre 1933), hasta que, finalmente, se dispuso que se erigiera en la Alameda de las Delicias frente a la Universidad Católica de Chile (decreto 5.674, de interior, de 21 1934, en DO. 28 noviembre 1934).

${ }^{68}$ Decreto 987, de relaciones exteriores, de 1928, minuta, en DO. 8 septiembre 1928.

${ }^{69}$ Decreto 1.290, de relaciones exteriores y comercio, de 1930, minuta, en $D O .14$ junio 1930. 


\section{CoOperación del EsTAdo CON LAS CONFESIONES}

RELIGIOSAS

\section{Cooperación económica}

La cooperación económica del Estado en materia religiosa se manifestó desde el principio por vías diversas, todas las cuales significaban que diversas instituciones religiosas, por conceptos diversos, no se veían en la necesidad de desembolsar sumas de dinero a favor del fisco porque eran titulares de exenciones generales o especiales que, en caso contrario, de no contar con ellas, les habrían significado un desembolso significativo. En otras palabras, el Estado renunciaba a percibir sumas de dinero para favorecer la religiosidad de los ciudadanos.

En ocasiones, esta cooperación económica estaba dir e c t a m e n t e relacionada con lo religioso, pues la ayuda se concedía en atención a la religiosidad de las personas, objetos o actividades con las que el Estado colaboraba. El Estado colaboraba con ellas porque la persona, el objeto o la actividad eran religiosas. En otras ocasiones, sin embargo, la colaboración con lo religioso era i n d i r e c t a , pues, si bien quien se beneficiaba era una entidad religiosa, el beneficio lo recibía no por ser una entidad religiosa, sino porque esta entidad desempeñaba una actividad debeneficencia que era lo que directamente apoyaba el Estado económicamente.

\section{a) exención de impuestos}

Una vía de cooperar con las instituciones religiosas fue eximirlas de impuestos, exención que podía ser general, beneficiando a todos quienes se encontrasen en la hipótesis definida por la norma, o especiales, favoreciendo a instituciones concretas.

Entre las generales estaba la exención de contribuciones definida por el propio texto constitucional cuando dispuso que "los templos y sus dependencias, destinados al servicio de un culto, estarán exentos de contribuciones" (art. 10 no 2 inc. 30). Cuando, poco después, se dictó el decreto ley que estableció el impuesto sobre bienes raíces, eximió expresamente del mismo a "las iglesias o templos destinados a algún culto religioso y las casas parroquiales"70. Y lo mismo sucedió en 1927 con la ley que reguló el impuesto territorial ${ }^{71}$, que repitió esta exención, pero en ésta se precisó que la exención beneficiaba a las casas parroquiales "habitadas por los funcionarios del culto y que no produzcan renta". En términos similares, el decreto ley que reguló la contribución de alcantarillado ${ }^{72}$ declaró exentos del pago de este impuesto "las iglesias o templos destinados a algún culto religioso; y las casas parroquiales habitadas por los funcionarios del culto y que no produzcan renta" (art. 2 c).Otra exención general fue establecida por la ley de impuesto sobre las herencias y donaciones ${ }^{73}$, en la que se declaraban exentos de los impuestos establecidos

\footnotetext{
${ }^{70}$ Decreto ley 756, de 16 de diciembre de 1925, art. 4 no 2, en DO. 21 diciembre 1925.

${ }^{71}$ Ley 4.174, en DO. 10 septiembre 1927; decreto 2.073, de hacienda, de 1929, que fija el texto definitivo de la ley 4.174, en DO. 10 octubre 1928.

${ }^{72}$ Decreto ley 192, de 13 de julio de 1932, en DO. 20 julio 1932.

${ }^{73}$ Ley 4.533, en DO. 21 enero 1929. Ley 5.427, en DO. 28 febrero 1934, art. 18 no 4.
} 
en la misma, las asignaciones y donaciones que se dejaren "para la construcción $o$ reparación de templos destinados al servicio de un culto" (art. $15 \mathrm{n}^{\circ} 1$ ).

No fueron las únicas exenciones tributarias, pues hubo otras, si bien se trataba de exenciones particularizadas a instituciones que lo solicitaban, haciendo uso de beneficios establecidos por la ley. Es lo que ocurrió con el impuesto complementario de la renta, del que fueron declarados exentos universidades ${ }^{74}$, congregaciones $^{75}$, monasterios $^{76}$, el arzobispado de Santiago ${ }^{77}$, obispados ${ }^{78}$, $\operatorname{colegios}^{79}$, seminario ${ }^{80}$, conservatorios $^{81}$. Y no sólo católicas, sino también de otras confesiones, como la Sociedad Misionera Sud Americana ${ }^{82}$, la Sociedad Evangélica Bautista ${ }^{83}$, la Iglesia Alianza Cristiana y Misionera ${ }^{84}$ o la Asociación Cristiana de Jóvenes ${ }^{85}$. Hubo, empero, algunos casos en que la solicitud para quedar eximido de este impuesto no fue aceptada, como ocurrió con el monasterio de la Visitación, de Santiago, para lo que se dio como razón que no se dedicaba ni a la enseñanza ni a la beneficencia, sino que "sólo se dedican a la oración y penitencia", por lo que no quedaba comprendido en la exención legal ${ }^{86}$. En efecto, el artículo único de la ley 4.265

${ }^{74}$ P. ej. la Universidad Católica de Valparaíso, decreto 4.171, de hacienda, de 1929, en DO. 2 agosto 1929 .

75 P. ej. la Congregación de la Casa de María. Decreto 608, de hacienda, de 1926, en DO. 27 abril 1926. La Congregación de las Hermanas de la Providencia de Chile, decreto 1.946, de hacienda, 1926, en DO. 29 octubre 1926; todos los establecimientos que mantenía en el país la Congregación de San Vicente de Paul, decreto 3.470, de hacienda, de 1929, en DO. 20 agosto 1929; la Orden de los R.P. Trinitarios de Santiago, decreto 6.677, de hacienda, de 1931, en DO. 2 noviembre 1931.

76 P. ej. el monasterio provincial del Buen Pastor, decreto 1.119, de hacienda, de 1926, en DO. 15 julio 1926; el monasterio de Oblatas Expiadoras del Santísimo Sacramento, decreto 1.386, de hacienda, de 1937, minuta, en DO. 24 mayo 1937.

77 Decreto 1.893, de hacienda, de 1928, en DO. 18 mayo 1928.

78 P. ej. el obispado de Concepción en la parte correspondiente a la renta presunta de los inmuebles ocupados por el seminario de Concepción y por el colegio de los Sagrados Corazones de la misma ciudad, decreto 5.457, de hacienda, de 1928, en DO. 4 enero 1929; el obispado de Valparaíso, decreto 3.794, de hacienda, de 1929, en DO. 4 septiembre 1929.

79 P. ej. el colegios de los Sagrados Corazones, San Pedro Nolasco, de las religiosas carmelitas de la caridad, San Ignacio, de las religiosas de la Inmaculada Concepción, todos de Santiago, decreto 2.547, de hacienda, de 1928, en DO. 13 julio 1928. Además, los colegios de las religiosas de la Inmaculada Concepción en el resto del país, decreto 2.990, de hacienda, de 1928, en DO. 7 agosto 1928. Se puede mencionar como ejemplo, además, el colegio de los Sagrados Corazones de Valparaíso, decreto 3.173, de hacienda, de 1928, en DO. 17 agosto 1928, y el colegio de las Carmelitas de la Caridad, de San Felipe, decreto 4.708, de hacienda, de 1929 , en DO. 27 agosto 1929.

${ }^{80}$ P. ej. el seminario de Chillán, decreto 3.726, de hacienda, de 1928, en DO. 26 septiembre 1928 .

${ }^{81}$ P. ej. el Conservatorio Católico de Música y Declamación de Santiago, decreto 469, de hacienda, 1929, en DO. 2 febrero 1929.

${ }^{82}$ Decreto 3.889, de hacienda, de 1930, en DO. 28 julio 1930.

${ }^{83}$ Decreto 6.235, de hacienda, de 1930, en DO. 12 diciembre 1930.

84 Ibíd.

85 Decreto s/n, de hacienda, de 1931, minuta, en DO. 30 septiembre 1931.

86 Decreto 6.233, de hacienda, de 1930, en DO. 12 diciembre 1930. Tampoco se concedió al convento de San Francisco de Parral, decreto 4.421, de hacienda, de 1931, en DO. 21 
disponía que podrían ser eximidos del impuesto "las instituciones de beneficencia pública o privada y los establecimientos particulares de instrucción, siempre que un decreto supremo así lo declare". La exención que pudiera decretarse, sin embargo, no daba derecho para reclamar la devolución de las sumas ya pagadas por impuestos correspondientes a períodos anteriores a la fecha de la exención ${ }^{87}$.

\section{b) liberación de derechos de internación}

Fue otra vía utilizada por el Estado para cooperar económicamente con las confesiones religiosas. En atención a la realidad religiosa que vivía el país por esos años, los beneficiados por las mismas fueron obispos ${ }^{88}$, monasterios ${ }^{89}$, conventos ${ }^{90}$, colegios $^{91}$, gobernaciones eclesiásticas ${ }^{92}$, catedrales $^{93}$, parroquias $^{94}$, comunidades religiosas $^{95}$, capillas $^{96}$, incluso capillas privadas como las capillas de fundos ${ }^{97}$.

Por lo general, se trata de objetos religiosos destinados al culto divino, pero, también se vieron beneficiados otros objetos, como un reloj de cuatro esferas destinado a la torre de la iglesia parroquial Precioso Corazón de María, de Santiago ${ }^{98}$, o un cuadro titulado "la muerte de San Francisco", pintado en Inglaterra por el padre Pedro Subercaseaux, destinado al monasterio de capuchinas de Santiago ${ }^{99}$. En ocasiones la exención era para artículos destinados a obras de beneficencia de entidades religiosas, como la que declaró exentos los artículos destinados a la calefacción del hospital del vicariato apostólico de la Araucanía, ubicado en

agosto 1931; ni al convento de San Francisco de Curicó, decreto 2.268, de hacienda, de 1934, en DO. 2 agosto 1934.

${ }^{87}$ Decreto 1.368, de hacienda, de 1936, minuta, en DO. 22 abril 1936.

${ }^{88}$ P. ej. el obispo de Rancagua, decreto 167, de hacienda, de 1926, DO. 23 mayo 1926.

${ }^{89}$ P. ej. el monasterio de descalzas de Santa Teresa, decreto 62, de hacienda, de 1926, en DO. 21 enero 1926.

${ }_{90}$ P. ej. el convento de los pasionistas de Santiago, decreto 63, de hacienda, de 1926, en DO. 21 enero 1926.

${ }_{91}$ P. ej. el colegio de los padres franceses de Santiago, decreto 64, de hacienda, de 1926, en DO. 21 enero 1926.

${ }_{92}$ P. ej. la gobernación eclesiástica de Valdivia, decreto 107, de hacienda, de 1926, en DO. 29 enero 1926.

${ }_{93}$ P. ej. la catedral de Temuco, decreto 5.528, de hacienda, de 1830, minuta, en DO. 15 noviembre 1930.

${ }^{94}$ P. ej. la parroquia San Lázaro de Santiago, decreto 670, de hacienda, de 1926, en DO. 7 mayo 1926.

${ }^{5}$ P. ej. los padres capuchinos de Santiago, decreto 147, de hacienda, de 1926, en $D O$. 5 febrero 1926; las Hermanitas de los Pobres, decreto 670, de hacienda, de 1930, minuta, en DO. 27 diciembre 1930.

${ }^{96}$ P. ej. la capilla del hospital de San Juan de Diosde Santiago, decreto 166, de hacienda, de 1926, en DO. 8 febrero 1926.

${ }_{97}$ P. ej. la capilla del fundo Santa Margarita, de Catemu, decreto 761, de hacienda, de 1926, en DO. 26 mayo 1926.

${ }^{98}$ Decreto 1.123 , de 1930, en DO. 8 marzo 1930.

${ }^{99}$ Decreto 1.563, de hacienda, de 1931, minuta, en DO. 9 mayo 1931. 
San José de la Mariquina ${ }^{100}$. Alguna vez, también, se liberó de derechos a una encomienda destinada al auditor de la nunciatura apostólica ${ }^{101}$.

En todo caso, los artículos destinados al culto divino no estaban genéricamente liberados de derechos para su internación, sino que se necesitaba previamente un decreto supremo, para solicitar el cual era menester cumplir los plazos que la legislación respectiva había establecido ${ }^{102}$. Por otra parte, no siempre las solicitudes de liberación de derechos eran aceptadas, y no son raras los rechazos de ellas ${ }^{103}$.

\section{c) facilitar ingresos económicos a las entidades religiosas}

En ocasiones, la cooperación económica no significaba evitar desembolsos a las instituciones religiosas, sino que facilitarles el ingresar dineros a sus arcas. Una vía para que ello ocurriera fueron las autorizaciones para realizar colectas, de las que se vieron beneficiados patronatos ${ }^{104}$, congregaciones religiosas ${ }^{105}$, obras parroquiales $^{106}$, asociaciones de fieles ${ }^{107}$, universidades ${ }^{108}$.

Otra vía fue la transferencia directa de dineros en beneficio de entidades religiosas, con el fin de ser invertidos en beneficio directo de dichas instituciones. Así, la tesorería provincial de Santiago puso a disposición del rector del seminario conciliar de Santiago la suma de $\$ 10.000$, cantidad que se destinaría a la construcción del estadio ubicado en dicho establecimiento ${ }^{109}$.

\section{Otros beneficios}

Además de la vigilancia en fiestas religiosas ${ }^{110} \mathrm{o}$ la clausura de establecimientos

${ }^{100}$ Ley 5.852, en DO. 6 agosto 1936.

${ }^{101}$ Decreto 1.112, de relaciones exteriores y comercio, de 1931, en DO. 1 diciembre 1931.

102 Ley 4.321, DO. 27 febrero 1928; decreto 681, de hacienda, de 1928 y decreto 1.424 , de hacienda, de 1928, en DO. 23 abril 1928.

103 P. ej. para el monasterio del Buen Pastor, de Valparaíso, decreto 510, de hacienda, de 1926, en DO. 14 abril 1926.

104 P. ej. el Patronato de la Mujer, decreto 2.766, de interior, de 1926, minuta, en DO. 25 agosto 1926; DO. 9 septiembre 1926.

105 P. ej. los padres trinitarios de la comuna de Yungay en beneficio de la labor social que realizaban en esa comuna y en la de Providencia, decreto 4.504, de interior, de 1927, en DO. 8 julio 1927.

106 P.ej. la olla infantil y los talleres de las escuelas parroquiales de la comuna de San Miguel, decreto 4.065, de interior, de 1927, en DO. 20 junio 1927.

107 P. ej. la Asociación de la Juventud Católica Femenina, decreto 6.055, de interior, de 1927, minuta, en DO. 25 octubre 1927.

${ }^{108}$ La Universidad Católica de Chile, a fin de allegar fondos para la reconstrucción del edificio destruido parcialmente por un incendio, orden ministerial 18 , de interior, de 15 de mayo de 1931, en DO. 18 mayo 1931.

109 Decreto 2.473, de hacienda, de 1928, minuta, en DO. 19 diciembre 1928.

110 Según el reglamento de servicio para jefes y oficiales de Carabineros de Chile (Reglamento $n^{\circ} 7$, de servicio para jefes y oficiales, de 6 de abril de 1932, decreto 1.069, de interior, de 1932, en DO. 18 mayo 1932) en todas las comisarías habría un segundo jefe con el título de oficial de órdenes, que lo sería el teniente más antiguo de la unidad, quien, entre sus deberes y atribuciones debía averiguar oportunamente, entre otras actividades, las fiestas y servicios 
que entorpecieran la actividad religiosa ${ }^{111}$, un beneficio que fue de gran utilidad para las confesiones religiosas se refirió a bienes inmuebles.

i) una modalidad de que se hizo uso en beneficio de entidades religiosas fue concederles título gratuito de dominio sobre terrenos destinados a fines sagrados, como eran los cementerios, concebidos por el derecho canónico de la época como lugares sagrados ${ }^{112}$. Así, es posible encontrar, especialmente en el sur de nuestro país, este tipo de concesiones en beneficio del obispado de Ancud, si bien, bajo la condición de que los terrenos "se mantengan destinados a los fines que tienen actualmente" ${ }^{113}$. Algo similar ocurre en estos años con el vicariato de la Araucanía ${ }^{114}$.

ii) otra modalidad de que se hizo uso en beneficio de entidades religiosas fue concederles el uso y goce gratuito de terrenos fiscales. Tales concesiones se hacían con finalidades precisas, a las que debían ser destinados por los beneficiarios, de manera que, de destinarlos a otros fines diversos, la concesión caducaba por el ministerio de la misma concesión ${ }^{115}$, concesiones que, una vez hechas, eran a veces prorrogadas hasta completarse el plazo de noventa años. Además de obispados, fue también beneficiarios de tales concesiones la Sociedad Conferencia de San Vicente de Paul ${ }^{116}$. En ocasiones, la concesión en uso y goce era el primer paso para llegar a la transferencia del dominio, debiendo, siempre, destinarse a fines precisos de beneficencia ${ }^{117}$.

religiosos que se verificaren en el radio de la comisaría y que pudieren necesitar vigilancia, a fin de remitir, con la debida oportunidad, las tropas necesarias.

${ }^{111}$ Entre las atribuciones y deberes especiales que la ley de municipalidades (decreto 1.642, de interior, de 1934, que fija el texto de la ley de municipalidades, en $D O .5$ mayo 1934) disponía para los alcaldes, estaba el de presentar al juzgado, en el mes de enero de cada año, la lista de los establecimientos de bebidas alcohólicas y "clausurar los negocios de la misma naturaleza que se encuentren a menos de doscientos metros de los templos" (art. $\left.111 \mathrm{n}^{\circ} 19\right)$.

112 Según el canon 1154 del Código de Derecho Canónico de 1917, vigente en estos años, "son lugares sagrados aquellos que se destinan al culto divino o a la sepultura de los fieles mediante la consagración o la bendición a que a ese efecto prescriben los libros litúrgicos aprobados".

${ }^{113}$ P. ej. decreto 553, de propiedad austral, de 1930, en DO. 7 mayo 1930, concede título gratuito de dominio sobre una hijuela mientras fuese destinada a cementerio en el lugar denominado $\mathrm{Nal}$, en la comuna y departamento de Ancud.

${ }_{114}$ Decreto 2.606, de propiedad austral, de 1930, en DO. 25 septiembre 1930, que concede título gratuito de dominio de un predio de 4,25 hectáreas ubicado en Calafquén, provincia de Valdivia.

${ }^{115}$ Así, se concedió al obispado de Antofagasta, a contar del 1 de enero de 1929 y por el plazo de 18 años, el uso gratuito de un terreno fiscal ubicado en la primera subdelegación del departamento de Antofagasta, con una cabida de 1.575 metros cuadrados, para que se destinase a asilo de ancianos. Expresamente dicha concesión se hacía "únicamente con el objeto de que el obispado de Antofagasta destine el referido terreno a la mantención del actual Asilo de Ancianos y caducará en caso de que fuere dedicado a otros fines"; ley 5.726, en DO. 8 octubre 1935, en beneficio del obispado de Antofagasta. Cuando el obispado de Ancud arrendó por cuatro años a un particular un predio fiscal de cinco hectáreas que se le había concedido para el establecimiento de una capilla y escuela pública, dicha concesión fuera dejada sin efecto por decreto (decreto 447, de propiedad austral, de 1931, en DO. 12 febrero 1931).

${ }^{116}$ Ley 5.733, en DO. 15 octubre 1935.

${ }^{117}$ Ley 5.733, en DO. 15 octubre 1935, que transfiere a la Sociedad Conferencia de San Vicente de Paul, de Temuco, el dominio de unos sitios cuyo uso y goce le habían sido concedidos con anterioridad, los que debían destinarse necesariamente para un asilo de ancianos y desvalidos. 
iii) además del dominio, o uso y goce gratuitos, también el arriendo de terrenos fiscales en beneficio de entidades religiosas. A fines de 1928 se permitió el arriendo de un terreno fiscal "con el objeto de establecer una casa habitación y una sala para difusión del culto evangélico", en el pueblo de Pampa Unión, subdelegación rural del departamento y comuna de Antofagasta, arriendo que se hacía por diez años ${ }^{118}$.

Pero no sólo la administración central del Estado era la que mostraba una actitud de colaboración con las confesiones religiosas, sino también las municipalidades, como el caso de la comisión de alcaldes de Magallanes que, aprobando el presupuesto para el año 1928, incluían un ítem para el reloj parroquial ${ }^{119}$. Algo similar ocurría con la municipalidad de Limache que, en su presupuesto para 1928, contemplaba la entrega de subvenciones para la escuela nocturna parroquial San Francisco ${ }^{120}$; o la municipalidad de Graneros, que en su presupuesto contemplaba una subvención para el dispensario parroquial de Codegua ${ }^{121}$. Y no faltó presupuesto para reparación de cementerios parroquiales ${ }^{122}$.

\section{CONCLUSIONES}

En las páginas que anteceden he hecho un repaso general de las primeras normas dictadas por el Estado de Chile relacionadas con la materia religiosa en los años inmediatamente siguientes a la separación entre el Estado y la Iglesia operada por la Constitución de 1925, años que corresponden al pontificado del papa Pío XI, que fue el Romano Pontífice reinante cuando Chile llevó adelante esa reforma trascendental, repaso que va desde la entrada en vigencia de dicha Constitución, el 18 de octubre de 1925, hasta el término de su pontificado, en febrero de 1939. Tres actitudes es posible advertir en estos primeros años.

Por de pronto, el Estado de Chile pasaba a ser un Estado laico, sin confesión religiosa oficial alguna, lo que estuvo muy presente desde el primer momento en las autoridades chilenas, entre las cuales no todos tenían un ideario personal religioso. Esto llevó al deseo de implementar desde el primer momento reformas a la legalidad vigente orientadas en dicha dirección, como la supresión de las clases de religión o la obligatoriedad de la precedencia del matrimonio civil respecto del religioso. De hecho, las clases de religión fueron suprimidas y el decreto de precedencia obligatoria del matrimonio civil estuvo redactado. Pero ninguna de dichas medidas prosperó porque primó en las autoridades chilenas del momento una laicidad que califico de $\mathrm{r}$ e a $\mathrm{l}$ is $\mathrm{t}$ a, es decir, una laicidad que no fue beligerante hacia lo religioso, sino que, aun cuando era consciente de que el Estado ya no era confesional, no desconoció lo religioso, sino que, con una dosis no menor de realismo, lo tomó en cuenta al momento de implementar reformas.

Esta laicidad r e a l is t a llevó a las autoridades de gobierno a una segunda

118 Decreto 5.369, de 1928, en DO. 4 enero 1929.

119 Acta de $22^{\mathrm{a}}$ sesión extraordinaria de alcaldes de Magallanes, celebrada en Punta Arenas, el 14 de noviembre de 1927, en DO. 23 marzo 1928.

${ }^{120}$ Decreto 1.184, de interior, de 1928, en DO. 9 abril 1928.

${ }^{121}$ Decreto 1.803, de interior, de 1928, en DO. 19 abril 1928.

122 P. ej. el cementerio parroquial de Tongoy, en DO. 22 agosto 1929. 
actitud, la de reconocer lo religioso como un factor social presente en la sociedad, en sus diversas manifestaciones. Esta presencia social venía desde años anteriores, pero no fue tarea del Estado empezar a desmontar ese entramado religioso-social, sino que, junto con reconocerlo, facilitó que siguiera estando presente y aún, en ocasiones, beneficiarse de él para fines que interesaban particularmente al Estado. Este reconocimiento se advierte no solo en el trato especial dispensado a la Iglesia católica inmediatamente después de la separación Estado-Iglesia, sino que, a lo largo de estos años, en materias tan diversas como la educación, capellanes, hospitales o cementerios; hubo concesiones especiales a párrocos y religiosos en atención a la calidad personal que investían, y no faltaron los honores a hombres vinculados a lo religioso. Más aún, cuando se consideró oportuno, el gobierno no dudó en pedir la colaboración de hombres y mujeres cuando consideró valioso valerse de sus aportes y ayudas.

Pero no se trató sólo de un reconocimiento de lo religioso como una factor social presente y operante en la sociedad chilena, sino que, a partir de este reconocimiento, las autoridades chilenas asumieron una tercera actitud: la de cooperar activamente con las confesiones religiosas, cooperación que asumió diversas modalidades siendo la económica, quizá, la más relevante. Ella se manifestó, por de pronto, permitiendo que las confesiones religiosas o algunas de las entidades a ellas vinculadas, no se vieran obligadas a desembolsar sumas de dinero al declararlas exentas de cargas tributarias que, de lo contrario, las obligaban a entregar sumas de dinero al Estado. Éste, así, al otorgar este beneficio a las entidades religiosas, dejaba de percibir ingresos que le correspondían legítimamente. Se trató de exenciones que beneficiaban a entidades religiosas en cuanto eran entidades religiosas, o a finalidades religiosas en cuanto religiosas, de manera que, de no haber tenido esa calidad, quedaban afectas al tributo. Hubo exenciones tributarias generales definidas en leyes de la República, o exenciones especiales impetradas al efecto. Otras modalidades de cooperación económica a las entidades religiosas fueron la liberación de derechos de internación, la autorización de colectas, las transferencias de dineros en beneficio de instituciones religiosas, las franquicias postales o la reducción de precio de pasajes ferroviarios.

A dichas ayuda dir e c t a s hay que agregar la cooperación in d i r e c t a, que también favoreció a entidades religiosas, pero ello en cuanto estas entidades religiosas desarrollaban actividades de beneficencia, que era las directamente apoyadas por el Estado. Pero lo interesante es que el carácter religioso de los actores no era óbice para la cooperación estatal.

La cooperación, empero, no sólo tuvo una dimensión económica, sino que revistió otras formas de ayuda, como consumo gratis de agua potable, ayudas municipales para diversos fines, concesión de títulos gratuitos de dominio, concesión de uso y goce gratuito de terrenos fiscales, arriendo de terrenos fiscales para fines religiosos, vigilancia en fiestas religiosas y hasta clausura de establecimientos que entorpecían la actividad religiosa.

Si en algún momento pudo haber en ciertos agentes del Estado de Chile el ánimo de que el Estado empezara a despreocuparse de lo religioso o, peor aún, que actuase contra él, tales actitudes fueron del todo minoritarias, pues la diversi- 
dad y variedad de normas dictadas en estos primeros años de separación entre lo temporal y lo espiritual muestran una actitud muy diversa: un Estado que asume una laicidad moderada por el realismo -laicidad realista- que lo lleva a reconocer lo religioso como un factor social presente en la sociedad chilena, a partir del cual asume una franca actitud de colaboración con lo espiritual. Las palabras proféticas pronunciadas por Pío XI con ocasión de la separación constitucional entre la Iglesia y el Estado, referidas específicamente a las relaciones con la Iglesia católica, bien pueden extenderse a todas las entidades religiosas, pues entre el Estado y ellas, al menos en estos primeros años, sin perjuicio de las ideas de los gobernantes de turno, hubo una "amigable convivencia".

\section{BiBLIOGRAFÍA}

\section{FUENTES IMPRESAS}

Código de Derecho Canónico (1917)

Constitución Política de la República de Chile (1833)

Constitución Política de la República de Chile (1925)

Código Civil de la República de Chile (1855)

Leyes, decretos leyes, decretos con fuerza de ley, decretos, reglamentos 1925-1939, en

Diario Oficial de la República de Chile (1925-1939) (= DO.)

Boletín Eclesiástico del Arzobispado de Santiago (1919-1929).

$1^{\circ}$ de junio de 1916. Mensaje leído por S. E. el Presidente de la República en la apertura de las sesiones ordinarias del Congreso Nacional (Santiago, Imprenta Nacional, 1916).

\section{BibLIOGRAFía GENERAL}

GonZÁlEz Errázuriz, Juan Ignacio, El vicariato castrense de Chile (Santiago, Ediciones Universidad de los Andes, 1996).

LEÓN LEÓN, Marco Antonio, Sepultura sagrada tumba profana. Los espacios de la muerte en Santiago de Chile, 1888-1932 (Santiago, Dirección de Bibliotecas, Archivos y Museos, Lom Ediciones, 1997.

Matte Varas, Joaquín, Historia del obispado castrense de Chile (Santiago, 2010)

Salinas Araneda, Carlos, Lecciones de derecho eclesiástico del Estado de Chile (Valparaíso, Ediciones Universitarias de Valparaíso, 2004).

- Las relaciones Iglesia-Estado en la América indiana: patronato, vicariato, regalismo, en NAVARRO Floria, Juan Gregorio (coord.), Estado, derecho y religión en América Latina (Buenos Aires, Marcial Pons, 2009, pp. 17-52; también en NAVArRo Floria, Juan G.; Milani, Daniela (a cura di), Le relazioni Chiesa-Stato in America Latina: introduzione storica, en Diritto e religione in America Latina (Bologna, Il Mulino, 2010), pp. 19-67.

- Las relaciones Iglesia-Estado en Chile en el siglo XIX, en SÁNCHEZ GAETE, Marcial (dir.), Historia de la Iglesia en Chile, III: Los nuevos caminos: la Iglesia y el Estado. (Santiago, Editorial Universitaria, 2011), pp. 231-277.

- El factor religioso en las Constituciones de la República de Chile, en MARTín SánCHEZ, Isidoro; GONZÁlEZ SÁNCHEZ, Marcos, 200 años de libertad religiosa en Iberoamérica, número monográfico de Derecho y Religión 7 (Madrid, 2012), pp. 203-230.

-120 años enseñando el derecho. Noticias biográficas de los profesores fallecidos del Curso 
de Leyes de los Sagrados Corazones de Valparaiso y de la Escuela de Derecho de la Pontificia Universidad Católica de Valparaíso (Valparaíso, Ediciones Universitarias de Valparaíso, 2014).

Somarriva Undurraga, Manuel, Evolución del Código Civil Chileno (Santiago, Editorial Nascimento, 1955 , pp. 52-55. 
